\title{
Formação para o SUAS no trabalho social com famílias indígenas em Santa Catarina
}

\author{
Formation for SUAS in social work with indigenous families in the state of Santa Catarina, \\ Brazil
}

\author{
Cíntia Régia Rodrigues ${ }^{1}$ \\ Cleide Gessele ${ }^{2}$
}

\section{RESUMO}

Esse texto tem por objetivo realizar uma análise do projeto de extensão "Formação sobre a diversidade étnico cultural para o SUAS", da Universidade Regional de Blumenau (FURB), desenvolvido no ano de 2019. O presente projeto ampliou a discussão em torno da diversidade étnico-cultural para o desenvolvimento de ações na Proteção Social Básica, normatizadas na Política Nacional de Assistência Social (PNAS, 2004) e nas Orientações Técnicas "Trabalho Social com as Famílias Indígenas na Proteção Social Básica” (2017). Na presente iniciativa de extensão, empreendemos a formação por meio de oficinas e rodas de conversa aos profissionais que atuam nos Centros de Referência de Assistência Social (CRAS) - assistentes sociais, psicólogos, educadores sociais e, ainda, a gestão do SUAS. O projeto foi realizado em parceria com os municípios de Ibirama, José Boiteux e Vitor Meireles, do estado de Santa Catarina, considerando que eles atuam na Terra Indígena Laklãnõ Xokleng. Conclui-se que a capacitação dos profissionais em torno do pluralismo étnico-cultural no Brasil e das políticas públicas, principalmente sobre a história indígena no Vale do Itajaí-SC, corrobora na prática profissional, ampliando as estratégias de intervenção com as famílias indígenas de forma coletiva, além de proporcionar a troca de experiências entre os participantes.

Palavras-chave: História indígena. Assistência social. Trabalho com as famílias indígenas.

\section{ABSTRACT}

This text aims to carry out an analysis of the extension project "Formation on ethnic cultural diversity for SUAS", from the Regional University of Blumenau (FURB), developed in 2019. This project expanded the discussion around ethnic-cultural diversity for the development of actions in Basic Social Protection, standardized in the National Social Assistance Policy (PNAS, 2004) and in the Technical Guidelines Social Work with Indigenous Families in Basic Social Protection (2017). In this extension initiative, we undertake the formation through workshops and conversation circles to professionals working in the Social Assistance Reference Centers (CRAS) - social workers, psychologists, social educators and also the SUAS management. The project was carried out in partnership with the municipalities of Ibirama, José Boiteux and Vitor Meireles, from the State of Santa Catarina, Brazil, considering that they operate in the Laklãnõ Xokleng Indigenous Territory. We conclude that the formation of professionals around ethnic-cultural pluralism in Brazil and public policies, mainly on the indigenous history in the Itajaí Valley-SC, corroborates in the professional

\footnotetext{
${ }^{1}$ Doutora em História pela Universidade do Vale do Rio dos Sinos, Rio Grande do Sul, Brasil; professora do Departamento de História e Geografia da Universidade Regional de Blumenau, Santa Catarina, Brasil (crrodrigues@furb.br).

2 Doutora em Serviço Social pela Universidade Federal de Santa Catarina, Brasil; professora do Departamento de Serviço Social da Universidade Regional de Blumenau, Santa Catarina, Brasil (cgessele@ furb.br).

Em Extensão, Uberlândia, v. 19, n. 2, p. 167-182, jul.-dez. 2020. 
practice, broadening the intervention strategies with indigenous families collectively, in addition to provide an exchange of experiences between participants.

Keywords: Indigenous history. Social assistance. Work with indigenous families.

\section{INTRODUÇÃO}

Este artigo analisa a experiência do projeto de extensão "Formação sobre a Diversidade Étnico-Cultural para o SUAS", dos Departamentos de História e Serviço Social da Universidade Regional de Blumenau (FURB), efetuado em parceria com os municípios de Ibirama, Vitor Meireles e José Boiteux, Santa Catarina, Brasil. O objetivo do projeto compreende a formação sobre a diversidade étnico-cultural, por meio de oficinas e rodas de conversa aos trabalhadores do Sistema Único de Assistência Social (SUAS) que atuam nos Centros de Referência de Assistência Social (CRAS), são eles: assistentes sociais, psicólogos, educadores sociais e, ainda, a gestão do SUAS.

Acreditamos que a extensão universitária pode levar à solidificação da relação universidade e sociedade local e regional. Destacamos que a FURB, a partir da Resolução no 53/2014, estabeleceu a Política de Desenvolvimento de Ações Permanentes e Articuladas de Temas Transversais (PATT), com o objetivo de estabelecer fundamentos e orientações para o planejamento e a avaliação de ações sobre os temas transversais, como Direitos Humanos, Gênero, Educação Ambiental, Relações étnico-raciais e Ensino de História e Cultura AfroBrasileira, Africana e Indígena a serem contempladas em todos os níveis de modalidades do processo de ensino, pesquisa, extensão e cultura da FURB.

Dessa forma, o projeto de extensão articula-se com a PATT tendo em vista que a função da Universidade nesse processo, por meio da extensão, na perspectiva de atender o compromisso com as demandas da sociedade, em particular, a demanda pela democratização do Estado e da sociedade.

Percebe-se a importância de uma formação sólida sobre as discussões em torno da diversidade étnica no Brasil, em especial tratando do contexto étnico-histórico do Vale do Itajaí-SC, aos trabalhadores do SUAS dos municípios de Ibirama, José Boiteux e Vitor Meireles, que possa contribuir na ampliação e aprimoramento das estratégias de intervenção para com as famílias indígenas. 
Para tanto, a importância da temática sobre a diversidade étnico-cultural para o SUAS remete à preocupação com a formação dos trabalhadores do SUAS que executam as ações socioassistenciais com as famílias indígenas nos CRAS, visto que a atuação deve ser pautada pelo respeito à diferença como direito assegurado aos povos indígenas pela Constituição Federal de 1988, bem como o trabalho social deve ser, na perspectiva do enfrentamento das desigualdades e discriminações a que foram historicamente submetidos, valorizando assim suas formas de organização e resistência.

É com base nesse pressuposto que foram realizadas formações para os trabalhadores do SUAS, os quais estão vinculadas as Secretarias Municipais de Assistência Social e que têm como desafio desenvolver o trabalho social com as famílias indígenas na perspectiva de autonomia e protagonismo, convívio familiar e comunitário, que, quando compreendidas a partir da realidade indígena, não têm a mesma conotação estipulada nas normativas e orientações já existentes do SUAS. Sua correta aplicação aos povos indígenas demanda a leitura sensível e respeitosa dos contextos históricos e culturais, bem como o compromisso político com a superação de visões equivocadas, estereotipadas advindas do colonialismo que ainda imperam na relação da sociedade nacional com as comunidades indígenas.

Inicialmente, apresentaremos um breve panorama da diversidade étnico-cultural, os povos indígenas e as políticas públicas tendo como ponto de partida a Constituição Federal (CF) de 1988; em seguida, descreveremos e analisaremos as oficinas realizadas com os trabalhadores do SUAS em 2019, na sequência, serão apontadas as considerações finais.

\section{Panorama da diversidade étnico-cultural, os povos indígenas e as políticas públicas no contexto da Constituição Federal}

A CF de 1988 é um marco na conquista dos direitos indígenas no Brasil, pois reconhece os povos indígenas como portadores de formas de vida com direito ao futuro, não mais como elementos do passado, em via de extinção. Esse códice estabelece um estado democrático de direito, que tem como alguns de seus objetivos fundamentais a construção de uma sociedade livre, justa, solidária, que tem como perspectiva a garantia de direitos fundamentais e sociais. Como responsabilidade pública estatal, fixa a Assistência Social no campo da Seguridade Social e estimula o reconhecimento da diversidade cultural na formação da sociedade brasileira. Nesse sentido, a Constituição promove o debate em torno da pluralidade étnico- 
cultural brasileira em diversos setores da sociedade nacional. A cultura brasileira é formada por diversos grupos étnicos, que configuram diferentes culturas.

Conforme Sahlins (2001), as culturas são dinâmicas e se reelaboram quando do contato com outras culturas.

A etnicidade supõe necessariamente uma trajetória (que é histórica e determinada por múltiplos fatores) e uma origem (que é uma experiência primária, individual, mas que também está traduzida em saberes e narrativas aos quais vem a se acoplar). O que seria próprio das identidades étnicas é que nelas a atualização histórica não anula o sentimento de referência à origem, mas até mesmo o reforça. É da resolução simbólica e coletiva dessa contradição que decorre a força política e emocional da etnicidade. (OLIVEIRA, 1999, p. 30).

As identidades indígenas devem ser compreendidas como plurais, com passado, presente e futuro. Já a palavra índio é um objeto socialmente construído, pois, quando da conquista da América, atribuiu-se aos povos nativos essa denominação. Essa imagem homogeinizante invisibilizou a diversidade dos povos americanos e foi construída constantemente ao longo da história do Brasil (RODRIGUES, 2002). Ser índio, porém, no final do século 20 e início do 21, é ser portador de um status jurídico, que lhe garante uma série de direitos. É fazer parte de uma coletividade que, segundo Oliveira (1998), por suas categorias e circuitos de interação, distingue-se da sociedade nacional e reivindica-se como "indígena". Ou seja, percebe-se como descendente de população de origem pré-colombiana.

De acordo com Carvalho (2003, p. 199), a CF/1988 redigiu e aprovou a constituição mais liberal e democrática que o país já teve, merecendo por isso o nome de Constituição Cidadã. Conforme o documento, em relação aos povos indígenas, em seu artigo 231: "São reconhecidos aos índios sua organização social, costumes, línguas, crenças e tradições, e os direitos originários sobre as terras que tradicionalmente ocupam, competindo à União demarcá-las, proteger e fazer respeitar todos os seus bens” (BRASIL, 1988).

Diante disso, os povos indígenas são reconhecidos pelo Estado Brasileiro, a partir das suas alteridades culturais. De acordo com Baniwã (2012), a CF modificou o rumo da história indígena no país, pois efetivou alguns direitos, trazendo também a superação da tutela e reconhecendo a capacidade civil dos índios, dessa forma, ocorrendo o abandono do pressuposto integracionista vigente a partir da Lei $n^{\circ} 6.001 / 1973$ - O Estatuto do Índio. 
Essas mudanças normativas do Estado também reverberaram na vida cotidiana dos indígenas, restabelecendo a autoestima em função das perspectivas de continuidade étnica, que remetem à reafirmação das identidades invisibilizadas. Ao mesmo tempo, o Estado deve empreender políticas públicas apropriadas à diversidade cultural, sendo que a autonomia e autodeterminação dos povos é uma garantia prevista na Convenção 169 da Organização Internacional do Trabalho (OIT), ratificada pelo Brasil em 2004. Isso implica em respeitar e acatar os pontos de vista das diferentes nações indígenas: oportunizar espaços de escuta e ouvir suas definições sobre o trabalho social que desejam (BRASIL, 2017).

Neste ínterim, destaca-se, também, que a Assistência Social como política de proteção social que vem sendo desenvolvida, desde 2004, pela Secretaria Nacional de Assistência Social, além de outras secretarias do Ministério do Desenvolvimento Social e Combate à Fome (MDS), elaborando ações em prol dos povos indígenas, que, lentamente vão sendo reconhecidas. Nesse sentido, a PNAS e o SUAS apontam à necessidade de refletir e aprofundar o debate em torno dos serviços socioassistenciais de atendimento aos diversos grupos étnicos no Brasil, no presente projeto, os grupos étnicos indígenas. Dessa forma, tratando-se dos povos indígenas, os seus direitos sociais devem ser modelados de acordo com práticas culturais das diversas etnias, respeitando a multiplicidade das identidades culturais.

No artigo 204 da CF/1988 encontram-se duas diretrizes da política de assistência social, relacionadas à descentralização político-administrativa e à participação da população e controle social, além disso, ainda no artigo 203, se ressalta que: "a assistência social será prestada a quem dela necessitar, independentemente de contribuição à seguridade social”. Dessa forma, entende-se que os benefícios e serviços são oferecidos a quem necessitar, acima de tudo, garantia dos direitos, e, principalmente respeitando as diferenças culturais, sociais e territoriais. Assim, a proposta elaborada por meio das Orientações Técnicas do Trabalho Social com as Famílias Indígenas na Proteção Social Básica, em 2017, pelo MDS, contribui para a efetivação do reconhecimento dos direitos indígenas a partir da Constituição de 1988, estabelecendo o acompanhamento culturalmente adequado das famílias indígenas no SUAS, conforme consta no documento:

O trabalho social com as famílias indígenas deve ter caráter preventivo, protetivo e proativo. Recomenda-se a adoção de uma abordagem metodológica clara, que promova uma reflexão crítica sobre a sua situação de vida e suas prováveis condicionantes socioeconômicas e culturais e 
favoreça a percepção das dimensões individuais e coletivas da situação vivenciada, a definição de estratégias e de projetos individuais e coletivos de superação da situação de vulnerabilidade social, com vistas ao efetivo usufruto dos direitos e à melhoria da qualidade de vida. (BRASIL, 2017, p. $40)$.

Nesse sentido, é fundamental que os trabalhadores do SUAS conheçam a conformação étnica brasileira e a história dos povos indígenas, em especial, no projeto de extensão em questão, sobre a história das populações indígenas do Vale do Itajaí-SC, dos processos de invisibilidade, de exclusões a que foram submetidos, reconhecendo as diferenças étnicas existentes e a região em que estão localizados, e, principalmente considerando suas condições enquanto cidadãos e sujeitos históricos, além disso, articular com a história indígena no Brasil.

Essa demanda em torno da diversidade étnico-cultural traz uma nova concepção para a Assistência Social brasileira no âmbito do SUAS como o campo dos direitos, da universalização dos acessos e da responsabilidade estatal. Dentre os serviços socioassistenciais no SUAS está a vigilância social, que se refere "à produção, sistematização de informações, indicadores e índices territorializados das situações de vulnerabilidade e risco pessoal e social que incidem sobre famílias/pessoas [...] vítimas de preconceito por etnia, gênero [...]” (BRASIL, 2005, não paginado).

A partir do cenário exposto, vislumbra-se a importância de uma formação sólida sobre as discussões em torno da diversidade étnica no Brasil, em especial tratando do contexto étnicohistórico do Vale do Itajaí-SC, aos profissionais do SUAS dos municípios de Ibirama, José Boiteux e Vitor Meireles, que possa contribuir na ampliação e aprimoramento das estratégias de intervenção para com as famílias indígenas na Terra Indígena Laklano Xokleng.

Atualmente, pelos dados do Censo Demográfico realizado pelo IBGE em 2010, a população indígena brasileira é de 896,9 mil, sendo identificadas 305 etnias e reconhecidas 274 línguas. Em Santa Catarina, segundo dados da Funai, Funasa e IBGE (Censo de 2010), no estado existem 16.041 indígenas, sendo que nesses números estão inclusos os indígenas que moram em Terras Indígenas (TI), nas zonas rurais e os que vivem nas cidades, nas zonas urbanas. Brighenti (2012) ressalta que, atualmente encontram-se 10.369 indígenas nas TI, divididos em três etnias: sendo 1.657 Guarani em 21 aldeias; os Kaingang somam 6.543 pessoas, distribuídas em cinco Terras Indígenas; Xokleng em Santa Catarina somam 2.169 pessoas localizados em duas TI: Ibirama Laklãno (localizada em José Boiteux, Vitor Meireles, Dr. 
Pedrinho e Itaiópolis) e Rio dos Pardos (localizada em Porto União). A TI Ibirama Laklãno está a 260 km de Florianópolis, estabelecida ao longo dos rios Hercílio e Plate, que desenham um dos vales que moldam a bacia do rio Itajaí-açú.

A TI foi criada em 1926, pelo governo de Santa Catarina, pelo Decreto ${ }^{\circ}$ 15, de 3 de abril, estabelecendo a primeira redução da TI reservada, uma área em torno de 20.000 hectares. Em 1914, o Serviço de Proteção aos Índios e Localização de Trabalhadores Nacionais (SPILTN) estabelece o contato com os indígenas em Santa Catarina, mais especificamente no Vale do Itajaí, criando o Posto Indígena Duque de Caxias, efetivando a "pacificação", que na verdade era uma prática da política indigenista nacional, que pretendia integrar os povos indígenas à sociedade nacional a partir dos moldes europeus, buscando que os mesmos fossem elementos participantes do progresso que estava em marcha no país, não reconhecendo as diversidades étnico-culturais existentes (RODRIGUES, 2011).

Foi reservada uma terra aos indígenas, com o objetivo de "liberar" as demais áreas para a colonização. Os limites territoriais propostos se aproximavam de 40.000 hectares, sendo que em 1926, conforme visto acima, estipulou-se uma redução considerável da terra. Já em 1956, o Serviço de Proteção aos Índios (SPI) oficializa a redução com a demarcação e registro da terra, passando, então, para 14.156,84 ha - sendo denominada "Reserva Dominial Indígena" (OLIVEIRA; BRIGHENTI, 2019). Em 1965 foi oficialmente demarcada e, em 1975, recebeu o nome de Ibirama ${ }^{3}$. Ainda na década de 1970, é iniciada a construção da Barragem Norte que traz benefícios às populações não indígenas da região, em função da contenção das enchentes, mas ao mesmo tempo acarreta inúmeros prejuízos aos indígenas. Atualmente, os Xokleng, os Guarani e Kaingang da TI Laklano-Ibirama vivem em oito aldeias: Sede, Pavão, Figueira, Palmeira, Toldo, Bugio, Coqueiro, e a aldeia Barragem.

Sendo assim, a formação da temática sobre a diversidade étnico-cultural, realizada em 2019 com os trabalhadores do SUAS, possibilitou avançar com as reflexões sobre o trabalho social com famílias indígenas a partir de pressupostos éticos, conhecimentos teórico-metodológicos e técnico-operativos, que têm por objetivo contribuir com "a convivência de pessoas unidas por laços consanguíneos, afetivos e/ou de solidariedade, a fim de proteger seus direitos, apoiá-las na função de proteção e socialização dos seus membros, bem como assegurar o convívio familiar e comunitário" (BRASIL, 2005). A seguir se discute a elaboração e

\footnotetext{
${ }^{3}$ Dados retirados do site: https://pib.socioambiental.org/pt/Povo:Xokleng. Acesso em: 5 jun. 2020. 
práticas das oficinas realizadas.

\section{Reflexões sobre as Oficinas realizadas com os Trabalhadores do SUAS}

Durante o ano de 2019, foram realizadas quatro oficinas com o objetivo de proporcionar reflexões, bem como, construções e/ou desconstruções sobre o trabalho social com as famílias indígenas a partir das demandas dos municípios participantes e também no contexto histórico existente na TI Ibirama, onde vivem os Laklãno-Xokleng, os Guarani e Kaingang.

A primeira oficina foi realizada no município de Ibirama, cujo tema foi a Etnia Guarani. Na ocasião, convidamos Vandreza Amante Gabriel ${ }^{4}$ para apresentar os resultados de sua pesquisa que originou sua dissertação de mestrado "Mbyá Guarani, alimentação e identidade no território". Após sua fala, realizamos uma roda de conversa com as trabalhadoras do SUAS que explanaram sobre as dificuldades de não terem conhecimento o suficiente para compreender as etnias, fragilizando as ações socioeducativas desenvolvidas com as famílias indígenas.

Outra questão abordada foi quanto à organização dos territórios indígenas. Reflexões sobre como a própria existência desses territórios se dá enquanto organização social estipulada pela sociedade ocidental contemporânea não indígena, argumento também validado com a afirmação de Costa, convergindo ao ponto de novas territorialidades igualitárias e multiterritorialidade.

Precisamos assim lutar concretamente para construir uma sociedade onde não só esteja muito mais democratizado o acesso a mais ampla multiterritorialidade - e a convivência de múltiplas territorialidades, onde estejam sempre abertas, também, as possibilidades para a reavaliação de nossas escolhas e a consequente criação de outras, territorialidades ainda mais igualitárias e respeitadoras da diferença humana. Isto porque o mundo não foi feito apenas para uma meia dúzia de privilegiados que podem efetivamente escolher em que território(s) prefere(m) a cada dia viver. Ou, de um modo mais paradoxal, apenas para aqueles que constroem um território-mundo moldado à sua exclusiva imagem e semelhança. (COSTA, 2004, p. 371).

A afirmação de Costa, aliada às discussões realizadas nessa primeira oficina, nos permite perceber que as noções de territorialidade para os indígenas são muito distintas das de pessoas

\footnotetext{
${ }^{4}$ Doutoranda no Programa de Pós-Graduação em Desenvolvimento Regional/ PPGDR-FURB e Mestre em Desenvolvimento Regional pela Universidade Regional de Blumenau/FURB (2014). Dados retirados do Currículo Lattes.
}

Em Extensão, Uberlândia, v. 19, n. 2, p. 167-182, jul.-dez. 2020. 
não indígenas, existindo uma noção diferenciada no que tange a propriedade privada. Remontando aos tempos do primeiro contato, podemos evidenciar em uma citação de Cristóvão Colombo em carta a Santagel de 1493, "Não pude saber se possuem bens privados, mas tive a impressão de que todos tinham direitos sobre o que cada um possuía, especialmente no que se refere aos víveres" (COLOMBO apud TODOROV, 1999, p. 47).

Outro debate importante que os trabalhadores do SUAS trouxeram foi a preocupação quanto ao grande número de violência contra crianças, adolescentes e mulheres nas aldeias. Para Borges (2016, p. 315) "as situações de risco, vulnerabilidade social e, mais grave, violação cotidiana de direitos decorrem, em grande parte, do confinamento a que foram forçados os indígenas e dos conflitos fundiários e interétnicos associados”. Os trabalhadores do SUAS dos municípios de Ibirama, José Boiteux e Vitor Meireles relatam e reforçam desde o início do projeto de extensão, no ano de 2018, que, até aquele momento, não terem recebido nenhuma formação por parte do estado e/ou município para atender as famílias indígenas, muito menos voltado as questões que envolvam violência sexual, violência doméstica e interfamiliar, uso de drogas, alcoolismo, bem como privação de alimentos. Para Borges (2016) a pobreza e extrema pobreza se associam aos ilícitos para geração de casos de violência em virtude do confinamento a que os indígenas foram submetidos nos últimos anos. Debate complexo e de extrema urgência a ser realizado por parte do SUAS, Rede de Proteção Integral aos Direitos das Crianças e Adolescentes, Conselho Tutelar, Saúde e Educação e Famílias Indígenas. Ou seja, para as famílias indígenas os temas como autonomia e protagonismo são caros, pois:

Tratam-se de conceitos que devem ultrapassar os limites da família para alcançar a coletividade: a redação do objetivo central do PAIF anuncia que autonomia e protagonismo se referem a "famílias e comunidades". O sentido político aqui se amplia quando relembramos que eles têm resguardado o direito coletivo à autodeterminação, tanto pela Constituição Federal quanto pela Convenção $\mathrm{n}^{\circ} 169$ da Organização Internacional do Trabalho (OIT, 1989) e pela Declaração das Nações Unidas sobre os Direitos dos Povos Indígenas (Nações Unidas, 2008). (BORGES, 2016, p. 319).

Para Borges (2016) as famílias indígenas teriam capacidades especiais de conduzir seus modos de vida, além de exercer o controle de seus assuntos internos. Assim,

a autonomia dos povos indígenas significa: ter autoridades próprias para tomar decisões em determinadas esferas e exercer poderes para regrar a vida interna e administrar seus assuntos políticos, econômicos, administrativos, culturais, educacionais, ambientais e de saúde, sobre uma base territorial com limites reconhecidos, com total liberdade para participar da vida política regional e nacional. Do ponto de vista indígena, autonomia é o guia a seguir 
rumo à construção de sociedades mais justas e democráticas, uma vez que assegura o exercício concreto do direito à livre determinação. (BORGES, 2016, p. 219-220).

Compreendemos que o trabalho social com famílias indígenas realizados no âmbito do SUAS, em especial pelos CRAS e Gestão que atendem às situações de violências e benefícios eventuais, possibilitem as famílias indígenas proteção social, bem como, "o exercício da autonomia e do protagonismo, atributos inter-relacionados e essenciais na conquista de direitos e alcance da cidadania" (BRASIL, 2012, p. 54).

A segunda oficina, realizada em José Boiteux, cujo tema foi a Colonização do Vale do Itajaí e a presença dos Laklãno Xokleng, possibilitou refletir sobre “quem são os Xokleng?". Dividimos em grupos as/os trabalhadores do SUAS que tinham como desafio responder tal questionamento. Após esse primeiro momento da oficina, realizamos uma explanação sobre contexto do grupo étnico, abordando os temas como território histórico, SPI e os conceitos assimilacionistas e de tutela validados inclusive por constituições anteriores à CF/1988.

Após essa conceituação acerca da etnia, os bolsistas de extensão apresentaram cinco trabalhos de conclusão do curso de Licenciatura Intercultural Indígena do Sul da Mata Atlântica ${ }^{5}$, objetivando trazer o protagonismo para os indígenas. Após a apresentação dos TCC, os cartazes, então, foram retomados para responder novamente à pergunta "Quem são os Laklãno-Xokleng?”. Dessa vez, as/os trabalhadores do SUAS, munidos de informações e compreendendo historicamente as situações de resistências e processos políticos que envolveram os indígenas Laklaño Xokleng, puderam novamente refletir sobre quem são esses povos.

A oficina possibilitou reflexões com a interação das/os trabalhadores do SUAS, considerando as respostas iniciais, em que os próprios profissionais realizaram a autocrítica sem que o grande grupo apontasse considerações, permitindo então que todos aprendessem com as colocações reducionistas/assimilacionistas, postas em um primeiro momento, e notassem o contraponto colocado pelos próprios profissionais sobre as respostas anteriormente inseridas. Nesse ponto, os objetivos alcançados na execução da oficina possibilitaram um embasamento e interação das discussões mais atuais sobre a questão indígena.

${ }^{5}$ Os trabalhos se encontram em: https://licenciaturaindigena.ufsc.br/. 
$\mathrm{Na}$ terceira oficina, denominada História dos Laklãno Xokleng e as políticas públicas, realizada no município de Vitor Meireles, os bolsistas de extensão deram sequência com a exposição dos trabalhos de conclusão do curso de Licenciatura Intercultural Indígena do Sul da Mata Atlântica.

Em adjacência exibimos o documentário Enchente: o outro lado da barragem norte ${ }^{6}$, que traz como principal questão os impactos causados pela barragem no convívio do povo Laklãnõ/Xokleng. O documentário foi produzido, em 2017, pela Café Cuxá Filmes e pelo Conselho Indigenista Missionário - Regional Sul, Conselho de Missão entre Povos Indígenas da IECLB, Fundação de Ensino Regional de Blumenau e Universidade Federal da Integração Latino Americana. Após o documentário, realizamos uma roda de conversa sobre os pontos que mais chamaram a atenção em relação às falas dos indígenas trazidas no filme.

Já na quarta e última oficina, realizada no município de José Boiteux, contamos com a presença de três mulheres indígenas, sendo duas da etnia Laklãnõ/Xokleng e uma da etnia Kaingang, com trajetórias distintas. Elas narraram aspectos de sua infância, educação, alimentação, idioma, crença e, principalmente, as condições vividas após a construção da barragem Norte.

A Construção da Barragem Norte iniciada em 1972 adveio agravando ao
extremo as condições de vida desta população em relação à interferência e
prejuízo nas tradições culturais, constantes deslocamentos territoriais,
obstrução e/ou dificuldade no acesso a políticas públicas, inacessibilidade
e/ou dificuldades de deslocamento entre aldeias, escolas e externamente por
decorrência das chuvas e alagamentos, ou seja, constantes e históricas
inoperâncias relativas às problemáticas para vivência deste povo.
(FONTOURA, 2015, p. 13).

Oportuno destacar que uma das falas da indígena da etnia Laklãnõ/Xokleng, no que concerne as tradições culturais, chama a atenção, pois, ao afirmar que hoje não pode mais dançar porque o pastor ensinou que Deus não gosta e isso caracteriza um pecado, dá ênfase ao quanto suas tradições foram sendo modificados ao longo dos anos. No processo de sociabilidade os povos indígenas vão reelaborando as suas culturas e, ao mesmo tempo, "pelo próprio instinto de sobrevivência, assumem novas estratégias produtivas e de convivência" (OLIVEIRA; ROSA; POMPEU, 2015, p. 378). Para tanto,

Tal fato dá abertura para novas possibilidades de interação entre os sujeitos, onde as relações se constroem e reconstroem em uma densa rede de

${ }^{6}$ Visualizar em https://www.youtube.com/watch?v=tpjM0JrXriY.

Em Extensão, Uberlândia, v. 19, n. 2, p. 167-182, jul.-dez. 2020. 
conectividade que se estrutura voluntária ou compulsoriamente, em torno das relações capitalistas de produção que se erguem. E, neste sentido, o capital não só cria novos desejos, como também transforma espaços, pessoas, ritmos de vida, desafiando os princípios do consenso e da legitimidade do poder econômico, da base político-territorial, da responsabilidade das decisões políticas, dentre outros, implicando em consequências que culminam no declínio da qualidade e significação da cidadania, das identidades, das formas de ser e viver dos cidadãos. (OLIVEIRA; ROSA; POMPEU, 2015, p. 379).

Frente a isso, destacamos que um dos eixos estruturantes do SUAS é a territorialização, ou seja, a PNAS assume os territórios como foco para compreensão das vulnerabilidades e riscos que ameaçam seus habitantes, bem como, garantir o processo de descentralização do SUAS de forma a aproximá-lo da vida cotidiana de seus usuários. "Os territórios indígenas, sob a forma de Terras Indígenas reconhecidas ou reivindicadas, são fundamentais para existência dos modos de vida indígenas, suas relações sociais e sistema de crenças e conhecimento" (BRASIL, 2017, p. 45).

Ao término das quatro oficinas, e fechando dois anos de formação com os trabalhadores do SUAS dos municípios de Ibirama, José Boiteux e Vitor Meireles, é notório que há desafios presentes para ambos os municípios no que tange ao atendimento as famílias indígenas preconizado pelo SUAS, pois,

\begin{abstract}
se tratando de realidade indígena, consiste em exercitar permanentemente a arte de vivenciar, refletir, compreender e acompanhar a complexa teia de relações e vinculações do movimento histórico vivenciado pelas etnias, até onde os determinantes sociais, culturais e econômicos poderão afetar as estruturas e a qualidade de vida dos sujeitos envolvidos em sua ação. Afinal, lutam por assegurar um modo de vida com outra temporalidade, demarcadas pela tradição e pelas forças da natureza. (OLIVEIRA; ROSA; POMPEU, 2015, p. 381).
\end{abstract}

Frente a isso, com intuito de dar continuidade às oficinas no ano de 2020, propusemos um questionário $^{7}$ para que os trabalhadores do SUAS o respondessem, no sentido de avaliar as oficinas realizadas no decorrer do ano, além de propor novos temas a serem explorados na continuidade do projeto de extensão. Ao tabular e analisar as respostas, verificamos que dois temas que apareceram de forma recorrente foram a necessidade de aprofundar os temas sobre "violências" e "saúde mental". Esse indicativo é de extrema relevância para que possamos (re)planejar o projeto de extensão com enfoque nas demandas que os municípios

\footnotetext{
${ }^{7}$ Foi elaborado no Google Docs um formulário para avaliar o projeto de extensão, enviado a todos os participantes dos três municípios envolvidos, intitulado "Formação sobre a diversidade étnica-cultural para o SUAS - 2019".
} 
necessitam.

Quanto à avaliação geral do projeto, os trabalhadores do SUAS, por meio do questionário respondido, reforçaram que as extensionistas abordaram os temas com muita propriedade sobre a realidade das famílias indígenas, sendo que as oficinas contribuíram imensamente para despertar ideias e reflexões acerca dos atendimentos para as famílias indígenas. Na fala de uma das trabalhadoras do SUAS, retirada do formulário de avaliação do projeto, enviado aos participantes, e citado acima, destacamos um relato de uma participante das oficinas do projeto de extensão que sintetiza outros depoimentos dos participantes: "eu cresci muito durante o projeto, cada discussão, cada fala, me fez refletir sobre meu olhar sobre as etnias étnico-cultural".

Diante das avaliações sobre o projeto de extensão "Formação sobre a Diversidade ÉtnicoCultural para o SUAS" acreditamos ter atingido uma das funções da Universidade que por meio da extensão se propõe atender o compromisso com as demandas da sociedade, em particular, possibilitar a reflexão sobre o atendimento e acompanhamento culturalmente adequado às famílias indígenas dos municípios catarinenses de Ibirama, José Boiteux e Vitor Meireles.

\section{CONSIDERAÇÕES FINAIS}

Partimos do pressuposto que avançamos quando pensamos que, hoje, a PNAS, por meio dos serviços socioassistenciais no âmbito do SUAS, garantem e/ou deveriam garantir os direitos das famílias indígenas frente a uma conjuntura histórica violenta e permeada por contradições que elaboraram várias visões equivocadas sobre a história indígena no Brasil.

É notório confirmar que a CF/1988 traz vários avanços em reconhecer o pluralismo étnico existente na sociedade nacional, que foi sendo certificado a partir de várias legislações, dentre elas, a implementação da PNAS (2004), do SUAS (2005) e das Orientações Técnicas do Trabalho Social com as Famílias Indígenas na Proteção Social Básica (2017).

Percebemos, a partir do trabalho apresentado e analisado acima, que apesar do avanço no conjunto de leis e regulamentações no que concerne ao trabalho social com as famílias indígenas, é fundamental garantir um processo de formação continuada para os trabalhadores do SUAS no intuito de qualificar a ação socioassistencial. Nesse sentido, reiteramos que 
conhecer e reconhecer a história do Vale do Itajaí-SC, no contexto das diversidades étnicas existentes, torna-se o alicerce necessário para o cumprimento de ações em torno da Proteção Social Básica dos municípios parceiros do projeto.

Constatamos já na primeira edição do projeto que para a grande maioria dos trabalhadores do SUAS o tema da diversidade étnico-cultural era desconhecido. No segundo ano do projeto, trabalhou-se intensamente no sentido de visibilizar cada vez mais a história indígena no Brasil e em especial no Vale do Itajaí-SC, compreendendo que os indígenas são protagonistas das suas vidas, da história nacional e regional. Aliado a isso, articulou-se o debate com as próprias demandas trazidas pelos participantes do projeto, reforçando de sobremaneira as especificidades étnico-culturais para o trabalho com as famílias indígenas da TI Ibirama.

Ainda, outro fator importante que observamos diz respeito à dinâmica de reunir os trabalhadores do SUAS dos três municípios participantes do projeto, pois, oportunizando esses espaços de discussão, foi possível promover a formação desses profissionais, bem como dos Secretários Municipais de Assistência Social a partir das especificidades e demandas de cada município, estabelecendo articulações que podem contribuir no desenvolvimento de ações que reconheçam e promovam as diversidades étnico-culturais na região e, quiçá, contribuam ainda para atenuar ou melhor extirpar o processo de invisibilização dos povos indígenas na história do Brasil.

\section{REFERÊNCIAS}

ALMEIDA, M. R. C. de. Os índios na história do Brasil no século XIX: da invisibilidade ao protagonismo. História Hoje, São Paulo, v. 1, n. 2, p. 21-39, 2012. Doi: 10.20949/rhhj.v1i2.39.

BRASIL. [Constituição (1988)]. Constituição da República Federativa do Brasil. Brasília, DF: Senado, 1988.

BRASIL. Ministério do Desenvolvimento Social. Secretaria Nacional de Assistência Social. Trabalho Social com Famílias Indígenas na Proteção Social Básica. Brasília, DF: MDS, 2017.

BRASIL. Ministério do Desenvolvimento Social e Combate à Fome. Secretaria Nacional de Assistência Social. Política Nacional de Assistência Social - PNAS 2004. Normativa operacional básica NOB/SUAS. Brasília, DF: MDS, 2005. 
BANIWA, G. A conquista da cidadania indígena e o fantasma da tutela no Brasil contemporâneo. In: RAMOS, A. R. (org.) Constituições nacionais e povos indígenas. Belo Horizonte: Editora UFMG, 2012. p. 206-227.

BORGES, J. C. “A sociedade brasileira nos fez pobres": assistência social e autonomia étnica dos povos indígenas: o caso de Dourados, Mato Grosso do Sul. Horizontes Antropológicos, Porto Alegre, ano 22, n. 46, p. 303-328, jul./dez. 2016. Doi: 10.1590/S010471832016000200011.

BRIGHENTI, C. Povos indígenas em Santa Catarina. In: Nötzold, A. L.; ROSA, H.; BRINGMANN, S. (org.). Etnohistória, história indígena e educação: contribuições ao debate. Porto Alegre: Pallotii, 2012. p. 37-65.

CARVAlHO, J. M. Cidadania no Brasil: o longo caminho. Rio de Janeiro: Civilização Brasileira, 2003.

FONTOURA, G. C. Direitos, desenvolvimento e povos indígenas: limites, possibilidades e desafios às políticas públicas na atualidade brasileira. 2015. 200 f. Dissertação (Mestrado em Desenvolvimento Regional) - Universidade Regional de Blumenau, Blumenau, 2015.

FUNDAÇÃO NACIONAL DO ÍNDIO. Disponível em: http://www.funai.gov.br/. Acesso em: 15 maio 2020.

INSTITUTO BRASILEIRO DE GEOGRAFIA E ESTATÍSTICA. Censo 2010. Características da população e dos domicílios: resultados do Universo. Disponível em: https://censo2010.ibge.gov.br/resultados.html. Acesso em: 20 maio 2020.

INSTITUTO SOCIOAMBIENTAL. Disponível em: https://www.socioambiental.org/pt-br. Acesso em: 15 maio 2020.

OLIVEIRA, J. P. Os indígenas na fundação da colônia: uma abordagem crítica. In: FRAGOSO, J. L. R.; GOUVEA, M. F. (org.). O Brasil colonial. Rio de Janeiro: Civilização Brasileira, 2014. p. 167-228.

OLIVEIRA, J. P. A viagem de volta. Etnicidade, política e reelaboração cultural no Nordeste Indígena. Rio de Janeiro: Contracapa, 1999.

OLIVEIRA, O.; BRIGHENTI, C. Cronologia Xokleng da luta pela terra - Parte 1 - Cimi Regional Sul - encarte. Xokleng Laklaño: a luta pela Terra Indígena que pode ser o marco de uma reparação histórica. Edição especial CIMI. Porantim, Brasília, Ano XL, n. 413. p. 4-5, 2019.

OLIVEIRA, J. P. (org). Indigenismo e territorialização: poderes, rotinas e saberes coloniais no Brasil contemporâneo. Rio de Janeiro: Contra Capa, 1998.

OLIVEIRA, R. N. C.; ROSA, L. C. S.; POMPEU, J. R. A. Serviço Social no contexto indígena: as transformações societárias e os desafios da profissão. O Social em Questão Ano XVIII, n. 33, p. 371-392, 2015. 
RODRIGUES, C. R. As imagens do índio na imprensa sul-riograndense 1884-1910. 2002. Dissertação (Mestrado em História) - Programa de Pós-Graduação em História, Universidade do Vale do Rio dos Sinos, São Leopoldo, 2002.

RODRIGUES, C. R. A construção da política indigenista na república brasileira a partir das ideias de modernidade. Tellus, v. 21, p. 203, jul.-dez. 2011. Doi: 10.20435/tellus.v0i21.248.

SAHLINS, M. Ilhas de História. São Paulo: J. Zahar, 2001.

TODOROV, T. A conquista da América: a questão do outro. São Paulo: Martins Fontes, 1999.

Submetido em 14 de julho de 2020.

Aprovado em 7 de outubro de 2020. 